Check for updates

Cite this: New J. Chem., 2017, 41,6105

Received 23rd March 2017, Accepted 24th May 2017

DOI: 10.1039/c7nj00969k

rsc.li/njc

\title{
Dimeric molecular clips based on glycoluril $\dagger$
}

\author{
Jan Sokolov, Tomas Lizal and Vladimir Sindelar (D) *
}

\begin{abstract}
Glycoluril dimers $\mathbf{4 a}$ and $\mathbf{4 b}$ were prepared and successfully transformed to glycoluril dimeric clips $\mathbf{7 a}$ and $\mathbf{7 b}$. ${ }^{1} \mathrm{H}$ NMR spectroscopy was used to reveal that the dimeric clip $\mathbf{7 b}$ with methyl substituents in its structure exists as a mixture of two distinct conformers in $\mathrm{D}_{2} \mathrm{O}$ at ambient temperature, while 7a possesses only one stable conformer under the same conditions due to its bulky phenyl substituents. The coalescence temperatures for $\mathbf{7 b}$ and its precursor $\mathbf{5 b}$ were determined. Both dimeric clips $\mathbf{7 a}$ and $7 \mathbf{b}$ formed complexes with methylviologen in $\mathrm{D}_{2} \mathrm{O}$ in which each of two clip-binding sites was occupied by one molecule of the guest. Thus, this study uncovers possible use of glycoluril dimers $\mathbf{4 a}$ and $\mathbf{4 b}$ as general building blocks for glycoluril-based supramolecular host molecules with two binding sites in their structure.
\end{abstract}

\section{Introduction}

Cucurbiturils are an important class of supramolecular host molecules that are prized for their ability to strongly and selectively bind organic molecules in water. ${ }^{1-6}$ These macrocycles consist of glycoluril units connected by methylene bridges. Recent progress in the chemistry of cucurbiturils enables the preparation of their functionalized derivatives, ${ }^{7-13}$ which can be covalently attached to various substrates and thus can be used for real applications. Along with the synthesis of cucurbituril derivatives, other supramolecular hosts based on glycoluril have been prepared, including anionic receptors bambusurils ${ }^{14-16}$ - and acyclic glycoluril oligomers. ${ }^{17-19}$ The latter group of compounds features high affinities toward anaesthetics, nitrosamines and various drugs. ${ }^{20-22}$ Despite recent progress in cucurbituril synthesis, there have been only two reported approaches dealing with the preparation of cucurbituril dimers. The first is based on the condensation of acyclic glycoluril hexamers with tetraaldehydes; ${ }^{23,24}$ the second relies on the conjugation of two monofunctionalized cucurbiturils. ${ }^{25}$ These cucurbituril dimers have been used as building blocks for the construction of supramolecular polymers and oligomers.

We decided to investigate a different approach for the preparation of dimeric cucurbiturils and their acyclic analogs. Our work was inspired by compound $\mathbf{4 a}$ (Scheme 1) previously reported in the literature. ${ }^{26,27}$ This compound contains two glycoluril units connected through phenylene links. Therefore, we wanted to

Department of Chemistry and RECETOX, Masaryk University, Kamenice 5, 62500 Brno, Czech Republic. E-mail: sindelar@chemi.muni.cz

$\dagger$ Electronic supplementary information (ESI) available: ${ }^{1} \mathrm{H}$ NMR spectra of all compounds, NMR titration data, and DFT calculation details (PDF). See DOI: 10.1039/c7nj00969k investigate whether this structural motif could be suitable for the construction of cucurbituril-based compounds. As a first approximation of a cucurbituril derivative, we selected to prepare dimeric clip 7a. The successful preparation of this compound should uncover the possibility of attaching methylene bridges to nitrogen atoms of sterically hindered glycoluril units of $\mathbf{4 a}$.

\section{Results and discussion}

The starting building block 4a for this dimeric clip has already been reported. ${ }^{26,27}$ According to the literature, compound $4 \mathbf{a}$ can be prepared by condensation of urea or urea derivative 8 (Fig. 1) with compound 3a in refluxing formic or acetic acid with a catalytic amount of sulfuric acid. However, when the synthesis was repeated in our laboratory under these conditions, only compound $\mathbf{9}$ with one glycoluril moiety was formed.

Fortunately, the reaction of urea with $3 \mathbf{a}$ in toluene in the presence of TFA provided dimer $\mathbf{4 a}$ in $95 \%$ yield. Compound $\mathbf{4 a}$ was then transformed to cyclic ether $\mathbf{5 a}$ by its reaction with paraformaldehyde in aqueous $\mathrm{HCl}$ (Scheme 1). Compound $\mathbf{5 a}$ was further reacted with hydroquinone to provide dimeric molecular clip 6 bearing OH groups on its terminal aromatic walls in $69 \%$ yield. Clip 6 was alkylated using 1,3-propanesultone to give water-soluble clip $7 \mathrm{a}$ in $68 \%$ yield.

The phenyl substituent present in glycoluril dimer $4 a$ can be a source of low reactivity and low solubility of this compound, as previously reported on the corresponding glycolurils for cucurbituril syntheses. ${ }^{8}$ Thus, we decided to prepare dimer $\mathbf{4 b}$ in which two phenyls are replaced by methyl substituents. The synthesis of $\mathbf{4 b}$ required precursor $\mathbf{3 b}$, which was not commercially available (unlike 3a) and had to be prepared from 1,4-diethynylbenzene (1) (Scheme 1). Alkyne 1 was deprotonated with 

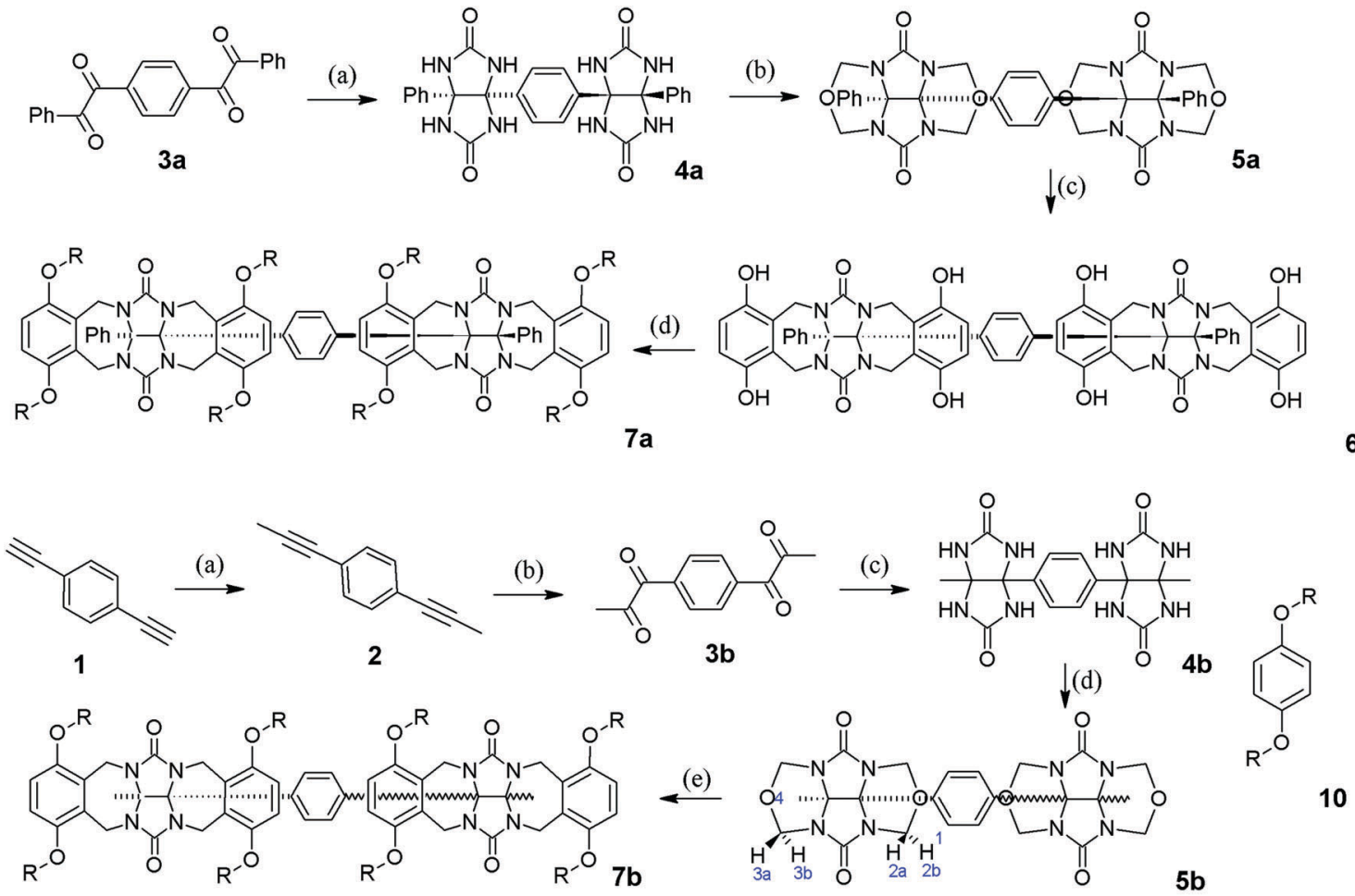

$\mathrm{R}=-\left(\mathrm{CH}_{2}\right)_{3} \mathrm{SO}_{3} \mathrm{Na}$

Scheme 1 Synthesis of molecular clips 7a and 7b. Conditions: (a) urea, PhMe/TFA, reflux, $12 \mathrm{~h}, 96 \%$; (b) $\mathrm{CH}_{2} \mathrm{O}, 7 \mathrm{M} \mathrm{HCl}$, reflux, $12 \mathrm{~h}, 91 \%$; (c) hydroquinone, TFA, reflux, $6 \mathrm{~h}, 69 \%$; (d) $9, \mathrm{NaOH}$, water/dioxane, $25{ }^{\circ} \mathrm{C}, 12 \mathrm{~h}, 68 \%$; (e) (1) $n$-BuLi, THF, $-78{ }^{\circ} \mathrm{C}, 1 \mathrm{~h}$, (2) $\mathrm{Mel}, 0-25{ }^{\circ} \mathrm{C}, 12 \mathrm{~h}, 95 \%$; (f) $\mathrm{RuCl}$, $\mathrm{NalO}_{4}, \mathrm{CCl}_{4} / \mathrm{MeCN} /$ water, $25^{\circ} \mathrm{C}, 2 \mathrm{~h}, 55 \%$; (g) urea, $0.3 \mathrm{M} \mathrm{HCl}, 25^{\circ} \mathrm{C}, 48 \mathrm{~h}, 77 \%$; (h) $\mathrm{CH}_{2} \mathrm{O}, 7 \mathrm{M} \mathrm{HCl}, 25^{\circ} \mathrm{C}, 36 \mathrm{~h}, 47 \%$; (i) 10, TFA/Ac $2 \mathrm{O}, 95{ }^{\circ} \mathrm{C}, 3 \mathrm{~h}, 59 \%$.

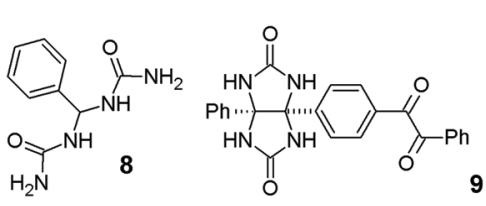

Fig. 1 Structures of selected compounds discussed in this work.

$n$-butyllithium and subsequently treated with methyl iodide to give 2. Compound 2 was oxidized to $3 \mathbf{b}$ using an $\mathrm{RuCl}_{3} / \mathrm{NaIO}_{4}$ mixture. Having compound $\mathbf{3 b}$ in our hands, we performed its reaction with urea in an aqueous $\mathrm{HCl} / \mathrm{CH}_{2} \mathrm{Cl}_{2}$ emulsion to obtain glycoluril dimer $\mathbf{4 b}$, which was transformed into cyclic ether $\mathbf{5 b}$ by its reaction with paraformaldehyde. Each of the glycoluril units of $\mathbf{5 b}$ bears methyl groups in the methine position, which are significantly smaller compared to phenyl groups in 5a. Cyclic ether $\mathbf{5 b}$ can react directly with compound 10 yielding molecular clip $\mathbf{7 b}$ in $59 \%$ yield. This approach was significantly less efficient in the case of $\mathbf{5 a}$ as bulky phenyl groups lower the reactivity of the ether groups towards the aromatic ring. This observation is in agreement with previously reported synthesis. ${ }^{16}$

\section{Conformational properties}

When recording the ${ }^{1} \mathrm{H}$ NMR spectra of compounds $5 \mathbf{b}$ and $7 \mathbf{b}$ at $30{ }^{\circ} \mathrm{C}$ in DMSO, we observed two signals instead of the expected one signal for each of their protons. These two sets of signals can be attributed to two distinct conformers, which were likely enabled by the rotation of two single $\mathrm{C}-\mathrm{C}$ bonds connecting the central phenylene group to the glycoluril moieties. The rotation was slow on the NMR timescale at $30{ }^{\circ} \mathrm{C}$; thus, the conformers were distinguished by their unique NMR spectra. Steric hindrance between methyl groups (attached to the methine carbon atoms of the glycoluril units) and the side walls of glycoluril units were likely the reason why the rotation was restricted. We decided to label the first conformer syn (the methyl groups located on the same side of the central phenylene group) and second anti (the methyl groups on opposite sides) (Fig. 2). Unfortunately, we could not distinguish which set of signals in the NMR spectra belonged to which conformer. Conformers of $\mathbf{5 b}$, as well as of $7 \mathbf{b}$, are present in a ratio of $58: 42$, which is based on the integration of the corresponding signals in the NMR spectra. The ratio corresponds to a $0.2 \mathrm{kcal} \mathrm{mol}^{-1}$ energy difference $(\Delta E)$ 


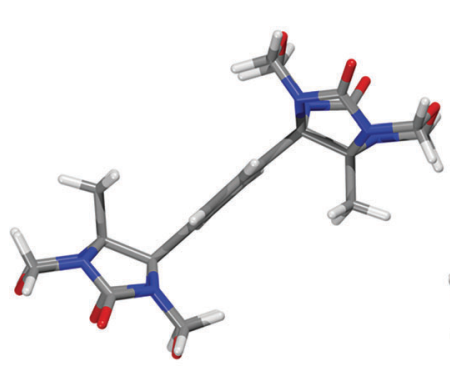

A)

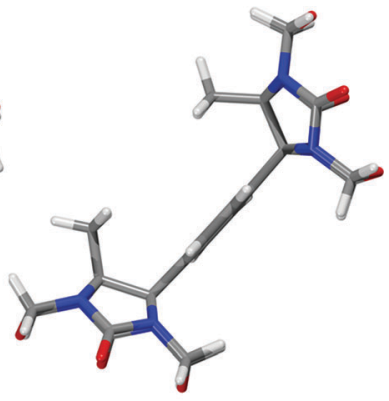

B)
Fig. 2 Optimized structures of anti (A) and syn (B) conformers of compound $\mathbf{5 b}$ obtained at the B3LYP/6-311G level of theory.

between the two conformers. The situation is different in the case of glycoluril dimer $\mathbf{4 b}$, which shows only one set of signals under the same conditions. This indicates that the rotation is fast on the NMR timescale as it is not restricted, due to the absence of the methylene side-groups featuring in $\mathbf{5 b}$ and $\mathbf{7 b}$. Glycoluril dimer $\mathbf{4 a}$ and its derivatives $5 \mathbf{a}$ and $7 \mathbf{a}$ also showed only one set of signals in their NMR spectra. However, these compounds distinguish themselves from $\mathbf{4 b}, \mathbf{5 b}$, and $\mathbf{7 b}$ by the presence of phenyl instead of methyl groups in the two methine positions of the glycoluril dimer core. We assume that two phenyl groups are too bulky to be fitted in the syn conformation. This is why $\mathbf{4 a}$ and its derivatives adopt only the sterically favorable anti conformation.

In order to gain information on the energy characteristics of the conformational changes in $\mathbf{5 b}$, the ${ }^{1} \mathrm{H}$ NMR spectra in DMSO- $d_{6}$ with temperature rising to $130{ }^{\circ} \mathrm{C}$ were recorded (Fig. 3). It was discovered that some signals in the NMR spectra show coalescence at a different temperature from the others. The coalescence temperature of signals $2 \mathrm{~b}$ and 4 was $90{ }^{\circ} \mathrm{C}$, while $1,2 \mathrm{a}$ and $3 \mathrm{~b}$ had already coalesced at $60{ }^{\circ} \mathrm{C}$. The reason why there are two coalescence temperatures observed instead of one may be that compound $\mathbf{5 b}$ possesses two $\mathrm{C}-\mathrm{C}$ bonds

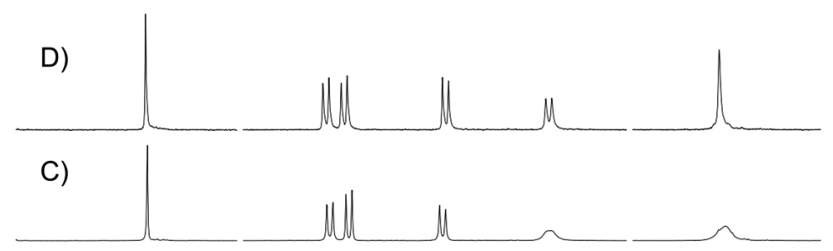

B)

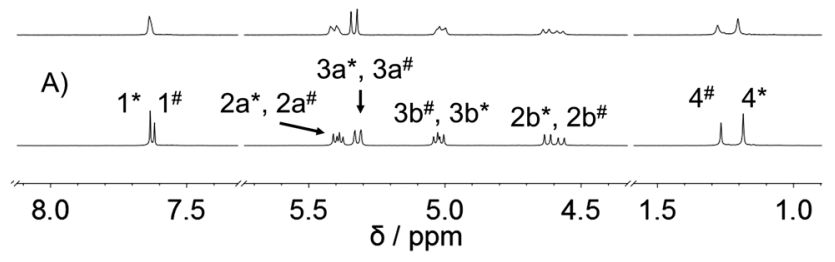

Fig. $3{ }^{1} \mathrm{H}$ NMR spectra $\left(500 \mathrm{MHz}\right.$, DMSO- $\left.d_{6}\right)$ of compound $\mathbf{5 b}$ recorded at $30{ }^{\circ} \mathrm{C}(\mathrm{A}), 60^{\circ} \mathrm{C}(\mathrm{B}), 90^{\circ} \mathrm{C}(\mathrm{C})$, and $130{ }^{\circ} \mathrm{C}(\mathrm{D})$. * denotes the signals of major conformers. ${ }^{\#}$ denotes the signals of minor conformers.
Table 1 Determined values of the activation Gibbs energy of the interconversion of conformers

\begin{tabular}{|c|c|c|c|c|c|}
\hline \multirow[b]{3}{*}{ Signals } & & \multicolumn{4}{|c|}{ Compound } \\
\hline & & \multicolumn{2}{|l|}{$5 \mathbf{b}$} & \multicolumn{2}{|l|}{$7 \mathbf{b}$} \\
\hline & & 1 & 4 & 1 & 4 \\
\hline$\Delta G^{\ddagger}\left(\mathrm{kcal} \mathrm{mol}^{-1}\right)$ & $\begin{array}{l}\text { Major } \rightarrow \text { minor } \\
\text { Minor } \rightarrow \text { major }\end{array}$ & $\begin{array}{l}18.42 \\
18.20\end{array}$ & $\begin{array}{l}18.95 \\
18.71\end{array}$ & $\begin{array}{l}21.05 \\
20.81\end{array}$ & $\begin{array}{l}21.14 \\
20.89\end{array}$ \\
\hline
\end{tabular}

around which the rotation occurs. Due to this, there is a possibility of two different kinds of rotational movements: (i) rotation of phenylene with respect to the glycoluril units and (ii) rotation of one glycoluril unit with respect to the other. The signals of protons 1 and 4 were used for the calculation of Gibbs activation energies of both rotations $\left(\Delta G^{\ddagger}\right)$ using the Eyring equation. The resulting values of $\Delta G^{\ddagger}$ are shown in Table 1. The whole calculation is described in detail in the ESI. $\dagger$

In contrast to $\mathbf{5 b}$, dimeric molecular clip $\mathbf{7 b}$ showed only a single coalescence temperature, $110{ }^{\circ} \mathrm{C}$. The values of $\Delta G^{\ddagger}$ of $7 \mathbf{b}$ calculated using singlets 1 and 4 were greater than those of $\mathbf{5 b}$ (Table 1). This means that the xylylene side walls of the clip $\mathbf{7 b}$ are a source of more significant steric hindrance than the cyclic ether groups of $\mathbf{5 b}$. In the case of compound $\mathbf{4 b}$, the $\Delta G^{\ddagger}$ might be determined by measurement of the NMR spectra at low temperature. However, compound $\mathbf{4 b}$ was insoluble in common organic solvents including DMF. The only suitable NMR solvent for this compound was DCOOD. The melting point of formic acid is $8.4{ }^{\circ} \mathrm{C}$ and therefore we could not measure the lowtemperature spectra and determine the $\Delta G^{\ddagger}$ of compound $\mathbf{4 b}$.

\section{Supramolecular properties}

The ability of dimeric clips $7 \mathbf{a}$ and $7 \mathbf{b}$ to act as supramolecular hosts was investigated by ${ }^{1} \mathrm{H}$ NMR spectroscopy. Inclusion complexes between viologens with cucurbiturils as well as their acyclic versions have been previously described. However, interactions of molecular clips resembling those present in dimeric clips $\mathbf{7 a}$ and $\mathbf{7 b}$ with viologen have not been reported. Thus, methylviologen $\mathbf{1 1}$ was selected as a suitable guest for supramolecular studies with dimeric clips $7 \mathbf{a}$ and $\mathbf{7 b}$ and their interactions in $\mathrm{D}_{2} \mathrm{O}$ (Fig. 4).

The aromatic signals of $\mathbf{1 1}$ underwent an upfield shift after addition of clips $7 \mathbf{a}$ and $7 \mathbf{b}$ to the guest solution. This indicates the formation of an inclusion complex between the clips and methylviologen. Since compounds $7 \mathbf{a}$ and $7 \mathbf{b}$ have two sites that could encapsulate guest 11, it was expected that these compounds would form 1:2 complexes, in which each clip arm holds one guest molecule 11. To prove the expected binding mode, the stoichiometry of the complex was determined by the continuous variation method (Job's plot). The maximum of Job's curve appeared approximately at $x$-coordinate $=0.66$ which proves that $1: 2$ complexation is predominant at equilibrium (Fig. S19 and $\mathrm{S} 20, \mathrm{ESI} \dagger$ ). This binding mode was further visualized by a model obtained by quantum chemical calculations (Fig. 5).

A plot of the chemical shifts of signals 1 and 2 of the guest was fitted to the binding isotherm of the $1: 2$ binding model to 


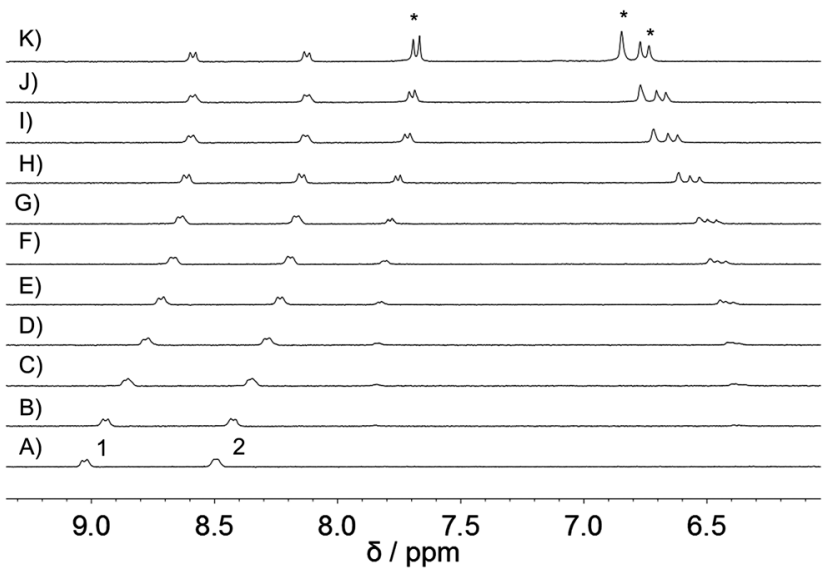

Fig. $4{ }^{1} \mathrm{H}$ NMR $\left(300 \mathrm{MHz}, \mathrm{D}_{2} \mathrm{O}\right)$ spectra of 11 in the absence $(A)$ and in the presence of 0.13 equiv. (B), 0.25 equiv. (C), 0.38 equiv. (D), 0.50 equiv. (E), 0.63 equiv. (F), 0.75 equiv. (G), 1.00 equiv. (H), 1.50 equiv. (I), 2.00 equiv. (J), and 3.00 equiv. $(K)$ of $7 \mathbf{b}$. ${ }^{*}$ denotes the signals of $\mathbf{7 b}$.

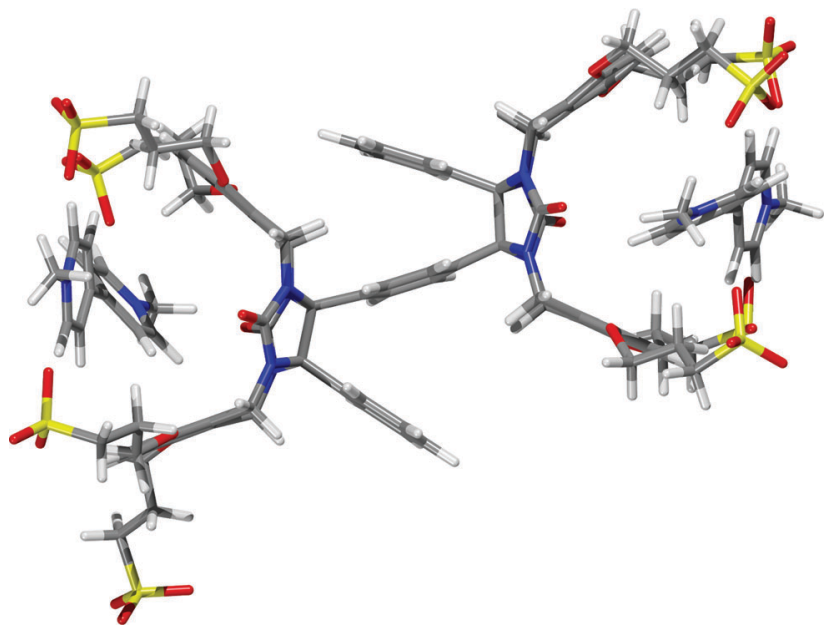

Fig. 5 Optimized structures of the $\mathbf{7 a} \cdot \mathbf{1} \mathbf{1}_{2}$ complex obtained using the PM6 method.

obtain the corresponding association constants (Table 2). Unlike clip 7a, the situation in the case of clip $7 \mathbf{b}$ was complicated by its ability to adopt two different conformers. In aqueous solution, the conformers were always in a ratio of $58: 42$; the equilibrium was not affected by the presence of guest 11 . We were not able to determine the association constants for separate conformers due to the presence of four binding sites (each conformer has two indistinguishable binding sites) during titration with 11. However, if the concentration of $\mathbf{1 1}$ was kept constant during the titration and the concentration of $\mathbf{7 b}$ was varied, it was possible to use the signals of guest $\mathbf{1 1}$ to establish the association constants describing the affinity of $\mathbf{1 1}$ towards an equilibrium mixture of both conformers of $\mathbf{7 b}$. The association constants determined for complexes $\mathbf{7 a} \cdot \mathbf{1 1}_{2}$ and $\mathbf{7 b} \cdot \mathbf{1 1}_{2}$ are summarized in Table 2.

Hosts $\mathbf{7 a}$ and $\mathbf{7 b}$ bind methylviologen $\mathbf{1 1}$ with a very similar overall affinity and in both cases the binding is associated with a negative cooperativity. The observed negative cooperativity
Table 2 Association constants of complexes of hosts $7 \mathbf{a}$ and $\mathbf{7 b}$ with $\mathbf{1 1}$ determined by NMR titrations in $\mathrm{D}_{2} \mathrm{O}$ at $30^{\circ} \mathrm{C}$

\begin{tabular}{llll}
\hline Host $\beta\left(\mathrm{M}^{-2}\right)$ & $K_{1}\left(\mathrm{M}^{-1}\right)$ & $K_{2}\left(\mathrm{M}^{-1}\right)$ & $4 K_{2} / K_{1}$ \\
\hline $7 \mathbf{a}$ & $(2.11 \pm 0.41) \times 10^{7}(1.28 \pm 0.25) \times 10^{4}(1.66 \pm 0.34) \times 10^{3}$ & 0.52 \\
$7 \mathbf{b}$ & $(1.31 \pm 0.42) \times 10^{7}$ & $(2.15 \pm 0.19) \times 10^{4}(6.3 \pm 1.4) \times 10^{2}$ & 0.12
\end{tabular}

can be rationalized by the inclusion of the guest molecule in the first binding side of the dimeric clip which causes conformational changes at the second binding site of the host. However, in our case the binding sites are separated by a rigid phenylene moiety. Therefore, we do not expect that the negative cooperativity is a result of conformational changes. We presume that binding of the first cation $\mathbf{1 1}$ affects the distribution of electron density in the host molecule, which makes it less attractive for another guest 11. Thus, electronic effects, rather than conformational changes, are the reason for the negative cooperativity. Finally, we determined the binding between 11 and model compound 12 to be $(8.82 \pm 0.77) \times 10^{3} \mathrm{M}^{-1}$ which is in good agreement with the values obtained for binding sites in dimeric clips.

\section{Conclusion}

We prepared compounds $7 \mathbf{a}$ and $\mathbf{7 b}$ as the first examples of glycoluril-based dimeric molecular clips. Clip $\mathbf{7 b}$, as well as other compounds derived from glycoluril dimer $\mathbf{4 b}$, can adopt two different conformations, which can be distinguished by means of NMR. On the other hand, free rotation is forbidden in compounds based on $\mathbf{4 a}$ due to the presence of the bulky phenyl substituent. Both dimeric clips $7 \mathbf{a}$ and $7 \mathbf{b}$ form complexes with methylviologen in a 1:2 ratio and with submillimolar stability in water. Our work demonstrated that structural motifs represented by compounds $\mathbf{4 a}$ and $\mathbf{4 b}$ can be converted to supramolecular hosts with two binding sites. Thus, a similar strategy should be applicable to the synthesis of dimers of acyclic glycoluril oligomers or cucurbituril dimers. The syntheses of these compounds are under development in our laboratory.

\section{Experimental section}

\section{General methods}

Starting materials were purchased from commercial suppliers and used without further purification. NMR spectra were recorded using a Bruker Avance 500 spectrometer operating at frequencies of $500.13 \mathrm{MHz}\left({ }^{1} \mathrm{H}\right)$ and $125.77 \mathrm{MHz}\left({ }^{13} \mathrm{C}\right)$, and a Bruker Avance 300 spectrometer operating at frequencies of 300.13 MHz $\left({ }^{1} \mathrm{H}\right)$ and $75.48 \mathrm{MHz}\left({ }^{13} \mathrm{C}\right)$. Both spectrometers were equipped with a BBFO probe. High-resolution mass spectra were recorded on an Agilent 6224 Accurate-Mass TOF LC-MS spectrometer using a multimode ESI/APCI ion source and a KDS Model 100 Series manual pump for sampling. 


\section{Synthetic procedures and characterization}

Glycoluril dimer (4a). Compound 3a (2.480 g, $7.43 \mathrm{mmol})$ was dissolved in toluene $(150 \mathrm{~mL})$; urea $(8.91 \mathrm{~g}, 0.149 \mathrm{~mol})$ and trifluoroacetic acid $(7.5 \mathrm{~mL})$ were added and the mixture was heated to reflux in a flask equipped with a Dean-Stark trap for $12 \mathrm{~h}$. A precipitate was formed at the bottom of the flask during the reaction. Toluene was then removed by decantation and the precipitate was treated with methanol $(200 \mathrm{~mL})$ and sonicated for $30 \mathrm{~min}$. The suspension was filtered and the solid was washed with acetone and dried in vacuo to give $4 \mathbf{a}$ as a white powder (3.605 g, 95\%). ${ }^{1} \mathrm{H}$ NMR (300 MHz, 96\% $\mathrm{D}_{2} \mathrm{SO}_{4}$, DMSO- $d_{6}$ as external reference) $\delta 6.72(\mathrm{t}, J=7.2 \mathrm{~Hz}, 2 \mathrm{H}), 6.59(\mathrm{t}, J=7.2 \mathrm{~Hz}$, $4 \mathrm{H}), 6.53(\mathrm{~s}, 4 \mathrm{H}), 6.24(\mathrm{~d}, J=7.8 \mathrm{~Hz}, 4 \mathrm{H}) .{ }^{13} \mathrm{C}$ NMR $(126 \mathrm{MHz}$, $96 \% \mathrm{D}_{2} \mathrm{SO}_{4}$, DMSO- $d_{6}$ as external reference) $\delta 161.86,131.69$, 130.92, 128.44, 126.85, 126.45, 124.68, 87.26, 85.82.

Cyclic ether (5a). Compound $4 \mathrm{a}(3.01 \mathrm{~g}, 5.89 \mathrm{mmol})$ was mixed with paraformaldehyde $(5.30 \mathrm{~g}, 0.177 \mathrm{~mol})$; water $(48 \mathrm{~mL})$ and $35 \% \mathrm{HCl}(72 \mathrm{~mL})$ were added and the suspension was heated to reflux for $16 \mathrm{~h}$. The suspension was cooled to RT and filtered. The solid material was washed with water and dried in vacuo to give $5 \mathbf{a}$ as a white powder $(3.64,91 \%) .{ }^{1} \mathrm{H}$ NMR (300 MHz, DMSO- $\left.d_{6}\right) \delta 7.14(\mathrm{~m}, 6 \mathrm{H}), 7.09(\mathrm{~m}, 4 \mathrm{H}), 6.93(\mathrm{~s} 4 \mathrm{H})$, $5.43(\mathrm{~m}, 8 \mathrm{H}), 4.56(\mathrm{~d}, J=11.4 \mathrm{~Hz}, 4 \mathrm{H}), 4.04(\mathrm{~d}, J=11.4 \mathrm{~Hz}, 4 \mathrm{H})$. ${ }^{13} \mathrm{C}$ NMR $\left(126 \mathrm{MHz}\right.$, DMSO- $\left.d_{6}\right) \delta 157.67,133.50,132.45,128.79$, 128.38, 128.08, 127.86, 78.79, 78.46, 71.60, 71.54. HR-MS (APCI-): $m / z\left[\mathrm{C}_{32} \mathrm{H}_{28} \mathrm{~N}_{8} \mathrm{O}_{7}+\mathrm{Cl}\right]^{-}$observed: 713.1884, $\mathrm{m} / \mathrm{z}$ $\left[\mathrm{C}_{32} \mathrm{H}_{28} \mathrm{~N}_{8} \mathrm{O}_{7}+\mathrm{Cl}\right]^{-}$calculated: 713.1881.

Dimeric clip (6). Compound 5a (1.20 g, $1.77 \mathrm{mmol})$ was dissolved in TFA (15 ml); hydroquinone was added (4.21 g, $38 \mathrm{mmol}$ ) and the mixture was heated to reflux for $6 \mathrm{~h}$ and then allowed to cool to RT. The product was precipitated with methanol $(100 \mathrm{ml})$ and the precipitate was collected by filtration. The crude product was dissolved in DMSO $(15 \mathrm{ml})$ at $80{ }^{\circ} \mathrm{C}$. Methanol $(80 \mathrm{ml})$ was added to the solution and the mixture was cooled to RT. The precipitate was collected by filtration and washed with methanol and diethyl ether to give 6 as a white powder $(1.29 \mathrm{~g}, 69 \%) .{ }^{1} \mathrm{H}$ NMR (300 MHz, DMSO- $\left.d_{6}\right) \delta$ $8.76(\mathrm{~s}, 4 \mathrm{H}), 8.67(\mathrm{~s}, 4 \mathrm{H}), 7.00(\mathrm{t}, J=7.9 \mathrm{~Hz}, 4 \mathrm{H}), 6.92(\mathrm{~d}, J=$ $7.4 \mathrm{~Hz}, 4 \mathrm{H}), 6.79(\mathrm{t}, J=7.1 \mathrm{~Hz}, 2 \mathrm{H}), 6.75(\mathrm{~s}, 4 \mathrm{H}), 6.52(\mathrm{~s}, 4 \mathrm{H}), 6.45$ $(\mathrm{s}, 4 \mathrm{H}), 5.32(\mathrm{~d}, J=15.9 \mathrm{~Hz}, 4 \mathrm{H}), 5.30(\mathrm{~d}, J=15.7 \mathrm{~Hz}, 4 \mathrm{H}), 3.53$ $(\mathrm{d}, J=15.9 \mathrm{~Hz}, 4 \mathrm{H}) 3.21(\mathrm{~d}, J=15.7 \mathrm{~Hz}, 4 \mathrm{H}) .{ }^{13} \mathrm{C} \mathrm{NMR}(126 \mathrm{MHz}$, DMSO- $\left.d_{6}\right) \delta 156.50,146.93,134.01,133.83,128.25,127.95$, 124.89, 124.82, 115.32, 115.19, 84.32, 84.14, 36.48, 36.29.

Dimeric clip (7a). Compound 6 (0.510 g, $0.49 \mathrm{mmol})$ was dissolved in $2.5 \mathrm{M} \mathrm{NaOH}(3.5 \mathrm{~mL})$. The solution was treated with 1,3-propanesultone $(0.911 \mathrm{~g}, 7.46 \mathrm{mmol})$ in dioxane $(3.5 \mathrm{~mL})$. The reaction mixture was stirred at RT for $8 \mathrm{~h}$. The resulting precipitate was collected by filtration, washed with methanol and suspended in $2.5 \mathrm{M} \mathrm{NaOH}(7 \mathrm{~mL})$. The suspension was again treated with 1,3-propanesultone $(2.139 \mathrm{~g}, 17.51 \mathrm{mmol})$ in dioxane $(9 \mathrm{~mL})$. The reaction mixture was stirred at RT for $8 \mathrm{~h}$. The resulting precipitate was collected by filtration and washed with methanol. The crude product was dissolved in water $(20 \mathrm{~mL})$ and precipitated with acetone $(120 \mathrm{~mL})$. The precipitate was collected by filtration, washed with methanol and diethyl ether and dried in vacuo to afford $7 \mathrm{a}$ as a yellowish powder $(0.728 \mathrm{~g}, 68 \%)$. ${ }^{1} \mathrm{H}$ NMR (300 MHz, D $\left.2 \mathrm{O}\right) \delta 7.22(\mathrm{~m}, 10 \mathrm{H}), 7.09(\mathrm{~s}, 4 \mathrm{H}), 7.03$ (s, 4H), 6.99 (s, 4H), $5.42(\mathrm{~d}, J=15.9 \mathrm{~Hz}, 4 \mathrm{H}), 5.38(\mathrm{~d}, J=15.9 \mathrm{~Hz}, 4 \mathrm{H})$, 4.18 (m, 16H), 4.00 (d, $J=15.9 \mathrm{~Hz}, 4 \mathrm{H}), 3.66$ (d, $J=15.9 \mathrm{~Hz}, 4 \mathrm{H})$, $3.22(\mathrm{~m}, 16 \mathrm{H}), 2.31(\mathrm{~m}, 16 \mathrm{H}) .{ }^{13} \mathrm{C}$ NMR (126 MHz, $\mathrm{D}_{2} \mathrm{O}$, 1,4-dioxane as internal reference) $\delta$ 159.82, 150.70,150.68, 134.62, 133.57, 129.51, 129.36, 129.03, 128.28, 127.93, 115.86, 115.72, 86.45, 86.12, 69.48, 69.43, 48.72, 48.65, 37.27, 25.18, 25.10. HR-MS (ESI+): $m / z\left[\mathrm{C}_{82} \mathrm{H}_{86} \mathrm{~N}_{8} \mathrm{Na}_{8} \mathrm{O}_{36} \mathrm{~S}_{8}+2 \mathrm{Na}\right]^{2+}$ observed: 1122.5939, $m / z\left[\mathrm{C}_{82} \mathrm{H}_{86} \mathrm{~N}_{8} \mathrm{Na}_{8} \mathrm{O}_{36} \mathrm{~S}_{8}+2 \mathrm{Na}\right]^{2+}$ calculated: 1122.5953.

1,4-Bis(1,2-dioxopropane-1-yl)benzene (3b). Compound $2^{28}$ $(0.771 \mathrm{~g}, 5.00 \mathrm{mmol})$ was dissolved in a mixture of $\mathrm{CCl}_{4}$ $(15.5 \mathrm{~mL})$ and $\mathrm{CH}_{3} \mathrm{CN}(15.5 \mathrm{~mL})$. A mixture of $\mathrm{NaIO}_{4}(6.42 \mathrm{~g}$, $30.02 \mathrm{mmol}), \mathrm{NaHCO}_{3}(67.3 \mathrm{mg}, 0.80 \mathrm{mmol})$ and $\mathrm{MgSO}_{4}(308.0 \mathrm{mg}$, $2.56 \mathrm{mmol})$ in water $(20 \mathrm{~mL})$ was added to the solution. Aqueous $0.01 \mathrm{M} \mathrm{RuCl}_{3}(4 \mathrm{~mL}, 0.04 \mathrm{mmol})$ was added and the reaction mixture was stirred at RT for $1.5 \mathrm{~h}$. The mixture was diluted with ethyl acetate $(100 \mathrm{ml})$ and the organic phase was separated from the precipitated salts by decantation. The organic phase was dried over $\mathrm{MgSO}_{4}$ and the solvents were removed by rotary evaporation. The crude product was dissolved in ethyl acetate and filtered through a plug of silica gel. The solvent was removed by rotary evaporation to give compound $3 \mathbf{b}$ as a yellow solid (0.605 g, 55\%). ${ }^{1} \mathrm{H}$ NMR (500 MHz, $\mathrm{CDCl}_{3}$ ): $\delta 8.13$ (s, 4H), 2.55 (s, 6H). ${ }^{13} \mathrm{C}$ NMR $\left(126 \mathrm{MHz}, \mathrm{CDCl}_{3}\right): \delta 199.30,189.93,136.15,130.64,26.22$.

Glycoluril dimer (4b). Compound $3 \mathbf{b}(1.42 \mathrm{~g}, 6.51 \mathrm{mmol})$ was dissolved in $\mathrm{CH}_{2} \mathrm{Cl}_{2}(20 \mathrm{~mL})$. Urea (5.06 g, $\left.92.7 \mathrm{mmol}\right)$ was dissolved in $0.3 \mathrm{M} \mathrm{HCl}(20 \mathrm{~mL})$. The solutions were mixed and stirred together at RT for 2 days. The resulting precipitate was collected by filtration, washed with water and acetone and dried in vacuo to give $4 \mathbf{b}$ as a white powder (1.95 g, 77\%). ${ }^{1} \mathrm{H}$ NMR (500 MHz, 95\% DCOOD) $\delta 7.80(\mathrm{~s}, 4 \mathrm{H}), 1.22(\mathrm{~s}, 6 \mathrm{H}) .{ }^{13} \mathrm{C}$ NMR (126 MHz, 95\% DCOOD) $\delta 162.24,137.44,127.58,81.68,79.21,22.70$.

Cyclic ether (5b). Paraformaldehyde (1.60 g, $53.3 \mathrm{mmol})$ was dissolved in $9 \mathrm{M} \mathrm{HCl}(20 \mathrm{~mL})$ at $60{ }^{\circ} \mathrm{C}$, the solution was cooled to RT and compound $4 \mathbf{b}(0.690 \mathrm{~g}, 1.78 \mathrm{mmol})$ was added and the solution was stirred for $24 \mathrm{~h}$. Water was added to the mixture $(11 \mathrm{~mL})$ and stirred for another $12 \mathrm{~h}$. The resulting precipitate was filtered, washed with water and dried in vacuo to give ether $\mathbf{5 b}$ as a white powder $(0.465 \mathrm{~g}, 47 \%)$. Compound $\mathbf{5 b}$ was obtained as a mixture of two conformers in a $58: 42$ ratio. ${ }^{1} \mathrm{H}$ NMR (500 MHz, DMSO- $d_{6}$ ) major conformer: $\delta 7.63(\mathrm{~s}, 4 \mathrm{H}), 5.40$ $(\mathrm{d}, J=11.3 \mathrm{~Hz}, 4 \mathrm{H}), 5.32$ (d, $J=11.2 \mathrm{~Hz} .4 \mathrm{H}) 5.01(\mathrm{~d}, J=11.2 \mathrm{~Hz}, 4 \mathrm{H})$, 4.62 (d, $J=11.3 \mathrm{~Hz}, 4 \mathrm{H}), 1.18(\mathrm{~s}, 6 \mathrm{H})$. Minor conformer: $\delta 7.62$ (s, 4H), 5.39 (d, $J=11.3 \mathrm{~Hz}, 4 \mathrm{H}), 5.32$ (d, $J=11.2 \mathrm{~Hz}, 4 \mathrm{H}), 5.03$ (d, $J=11.2 \mathrm{~Hz}, 4 \mathrm{H}), 4.57$ (d, $J=11.3 \mathrm{~Hz}, 4 \mathrm{H}), 1.27$ (s, 6H). ${ }^{13} \mathrm{C}$ NMR (126 MHz, DMSO- $d_{6}$ ) major conformer: $\delta$ 157.56, 134.84, 128.73, 77.87, 73.96, 71.30, 70.57, 18.77. Minor conformer: $\delta$ 157.56, 134.59, 128.73, 77.89, 73.89, 71.30, 70.57, 19.14. HR-MS (APCI-): $\mathrm{m} / \mathrm{z}$ $\left[\mathrm{C}_{24} \mathrm{H}_{26} \mathrm{~N}_{8} \mathrm{O}_{7}+\mathrm{Cl}\right]^{-}$observed: 589.1570, $m / z\left[\mathrm{C}_{24} \mathrm{H}_{26} \mathrm{~N}_{8} \mathrm{O}_{7}+\mathrm{Cl}\right]^{-}$ calculated: 589.1568 .

Dimeric clip (7b). Compound 5b (0.460 g, $0.83 \mathrm{mmol})$ and compound $10(2.31 \mathrm{~g}, 5.83 \mathrm{mmol})$ were dissolved in a mixture of TFA $(12 \mathrm{~mL})$ and acetic anhydride $(12 \mathrm{~mL})$. The solution was heated to $95{ }^{\circ} \mathrm{C}$ for $4 \mathrm{~h}$. The solvents were removed by rotary evaporation and the resulting solid was washed with 
methanol $(200 \mathrm{~mL})$. The crude product was dissolved in water $(15 \mathrm{~mL})$ and precipitated with acetone $(120 \mathrm{~mL})$. The precipitate was filtered and dissolved in water $(20 \mathrm{~mL})$; the $\mathrm{pH}$ of the solution was adjusted to 7 using $1 \mathrm{M} \mathrm{NaOH}$ and the water was removed by rotary evaporation. The resulting solid was washed with methanol and diethyl ether and dried in vacuo to afford $7 \mathbf{b}$ as a yellowish solid (1.01 g, 59\%). ${ }^{1} \mathrm{H}$ NMR $\left(500 \mathrm{MHz}, \mathrm{D}_{2} \mathrm{O}\right)$ major conformer: $\delta 7.71(\mathrm{~s}, 4 \mathrm{H}), 7.03$ (s, 4H), $6.94(\mathrm{~s}, 4 \mathrm{H}), 5.41(\mathrm{~d}, J=16.3 \mathrm{~Hz}, 4 \mathrm{H}), 5.23(\mathrm{~d}, J=15.7$ $\mathrm{Hz}, 4 \mathrm{H}), 4.25(\mathrm{~m}, 4 \mathrm{H}), 4.15(\mathrm{~m}, 20 \mathrm{H}), 3.18(\mathrm{~m}, 16 \mathrm{H}), 2.28$ $(\mathrm{m}, 16 \mathrm{H}), 1.31(\mathrm{~s}, 6 \mathrm{H})$. Minor conformer: $\delta$ 7.74, $(\mathrm{s}, 4 \mathrm{H}), 7.03$ $(\mathrm{s}, 4 \mathrm{H}), 6.91(\mathrm{~s}, 4 \mathrm{H}), 5.41(\mathrm{~d}, J=16.3 \mathrm{~Hz}, 4 \mathrm{H}), 5.29(\mathrm{~d}, J=$ $15.7 \mathrm{~Hz}, 4 \mathrm{H}), 4.25(\mathrm{~m}, 4 \mathrm{H}), 4.15(\mathrm{~m}, 20 \mathrm{H}), 3.18(\mathrm{~m}, 16 \mathrm{H})$, $2.28(\mathrm{~m}, 16 \mathrm{H}), 1.36(\mathrm{~s}, 6 \mathrm{H}) .{ }^{13} \mathrm{C} \mathrm{NMR}\left(126 \mathrm{MHz}, \mathrm{D}_{2} \mathrm{O}\right.$, 1,4-dioxane as internal reference) major conformer: $\delta 159.30$, 150.82, 135.96, 129.49, 128.92, 127.84, 115.92, 115.83, 85.04, 80.64, 69.66, 69.51, 48.64, 37.41, 35.97, 25.10, 18.95. Minor conformer: $\delta$ 159.30, 150.72, 135.92, 129.67, 128.92, 127.84, 115.92, 115.63, 85.11, 80.36, 69.66, 69.44, 48.64, 37.38, 35.97, 25.10, 18.69. HR-MS (ESI+): $m / z\left[\mathrm{C}_{72} \mathrm{H}_{82} \mathrm{~N}_{8} \mathrm{Na}_{8} \mathrm{O}_{36} \mathrm{~S}_{8}+2 \mathrm{Na}\right]^{2+}$ observed: $1060.5797, \mathrm{~m} / z\left[\mathrm{C}_{72} \mathrm{H}_{82} \mathrm{~N}_{8} \mathrm{Na}_{8} \mathrm{O}_{36} \mathrm{~S}_{8}+2 \mathrm{Na}\right]^{2+}$ calculated: 1060.5796.

Glycoluril derivative (9). Compound 3a (0.334 g, $1.01 \mathrm{mmol})$ and compound $8^{29}(0.853 \mathrm{~g} 4.10 \mathrm{mmol})$ were dissolved in acetic acid $(15 \mathrm{~mL})$ and $96 \% \mathrm{H}_{2} \mathrm{SO}_{4}(0.5 \mathrm{~mL})$ was added. The solution was heated to reflux for $4 \mathrm{~h}$, cooled to RT and poured into water $(100 \mathrm{~mL})$, which resulted in the formation of a precipitate. The precipitate was collected by filtration, washed with water and acetone and dried in vacuo to give 8 as a pale yellow powder $(0.411 \mathrm{~g}, 96 \%) .{ }^{1} \mathrm{H}$ NMR (500 $\mathrm{MHz}, 95 \%$ DCOOD) $\delta 7.88(\mathrm{~d}, J=7.0 \mathrm{~Hz}, 2 \mathrm{H}),, 7.83(\mathrm{t}, J=7.5 \mathrm{~Hz}, 1 \mathrm{H})$, $7.80(\mathrm{~d}, J=9.0 \mathrm{~Hz}, 2 \mathrm{H}), 7.62(\mathrm{t}, J=7.0 \mathrm{~Hz}, 2 \mathrm{H}), 7.57(\mathrm{~d}, J=$ $9.0 \mathrm{~Hz}, 2 \mathrm{H}), 7.31(\mathrm{~m}, 2 \mathrm{H}), 7.20(\mathrm{~m}, 3 \mathrm{H}) .{ }^{13} \mathrm{C} \mathrm{NMR}(126 \mathrm{MHz}$, 95\% DCOOD) $\delta 195.78,195.41,162.80,143.11,135.99,134.85$, 132.95, 132.29, 129.96, 129.63, 129.51, 129.32, 128.42, 128.08, 126.91, 83.88, 83.31.

Monomeric clip (12). Diphenyl glycoluril cyclic ether ${ }^{30}$ (1.021 $\mathrm{g}, 27.96 \mathrm{mmol})$ and compound $\mathbf{1 0}^{21}$ (3.198 $\left.\mathrm{g}, 80.28 \mathrm{mmol}\right)$ were dissolved in a mixture of TFA $(15 \mathrm{~mL})$ and acetic anhydride $(15 \mathrm{~mL})$. The solution was heated to $95{ }^{\circ} \mathrm{C}$ for $4 \mathrm{~h}$. The solvents were removed by rotary evaporation and the resulting solid was washed with methanol $(200 \mathrm{~mL})$. The crude product was dissolved in water $(15 \mathrm{~mL})$ and precipitated with acetone $(120 \mathrm{~mL})$. The precipitate was collected by filtration and dissolved in water $(20 \mathrm{~mL})$; the $\mathrm{pH}$ of the solution was adjusted to 7 using $1 \mathrm{M} \mathrm{NaOH}$ and the water was removed by rotary evaporation. The resulting solid was washed with methanol and diethyl ether and dried in vacuo to afford compound 12 as a yellowish solid (0.961 g, 32\%). ${ }^{1} \mathrm{H}$ NMR (300 MHz, $\left.\mathrm{D}_{2} \mathrm{O}\right) \delta 7.29$ $(\mathrm{m}, 10 \mathrm{H}), 6.90(\mathrm{~s}, 4 \mathrm{H}), 5.38(\mathrm{~d}, J=16.0 \mathrm{~Hz}), 4.12(\mathrm{~m}, 8 \mathrm{H}), 3.93$ $(\mathrm{d}, J=16.0 \mathrm{~Hz}), 3.20(\mathrm{~m}, 8 \mathrm{H}), 2.28(\mathrm{~m}, 8 \mathrm{H}) .{ }^{13} \mathrm{C}$ NMR $(126 \mathrm{MHz}$, $\mathrm{D}_{2} \mathrm{O}, 1,4$-dioxane as internal reference) $\delta 160.11,150.71,133.60$, $129.71,129.39$, 128.87, 128.22, 115.72, 86.67, 69.44, 48.70, 37.34, 25.13. HR-MS (ESI-): $m / z\left[\mathrm{C}_{44} \mathrm{H}_{46} \mathrm{~N}_{4} \mathrm{Na}_{4} \mathrm{O}_{18} \mathrm{~S}_{4}-\mathrm{Na}\right]^{-}$ observed: $1049.1937, \mathrm{~m} / z\left[\mathrm{C}_{44} \mathrm{H}_{46} \mathrm{~N}_{4} \mathrm{Na}_{4} \mathrm{O}_{18} \mathrm{~S}_{4}-\mathrm{Na}\right]^{-}$calculated: 1049.1930.

\section{Competing financial interest}

The authors declare no competing financial interest.

\section{Acknowledgements}

This work was supported by the Czech Science Foundation (13-15576S) and the MEYS CR (projects LM2011028 and LO1214). Jan Sokolov acknowledges the Brno PhD Talent Scholarship program funded by the Brno City Municipality. We thank Dr Robert Vícha (Tomas Bata University in Zlín) for helpful discussion.

\section{References}

1 W. A. Freeman, W. L. Mock and N. Y. Shih, J. Am. Chem. Soc., 1981, 103(24), 7367-7368.

2 J. Kim, I.-S. Jung, S.-Y. Kim, E. Lee, J.-K. Kang, S. Sakamoto, K. Yamaguchi and K. Kim, J. Am. Chem. Soc., 2000, 122(3), 540-541.

3 J. W. Lee, S. Samal, N. Selvapalam, H.-J. Kim and K. Kim, Acc. Chem. Res., 2003, 36(8), 621-630.

4 J. Lagona, P. Mukhopadhyay, S. Chakrabarti and L. Isaacs, Angew. Chem., Int. Ed., 2005, 44(31), 4844-4870.

5 E. Masson, X. Ling, R. Joseph, L. Kyeremeh-Mensah and X. Lu, RSC Adv., 2012, 2(4), 1213.

6 S. J. Barrow, S. Kasera, M. J. Rowland, J. del Barrio and O. A. Scherman, Chem. Rev., 2015, 115(22), 12320-12406.

7 D. Lucas, T. Minami, G. Iannuzzi, L. Cao, J. B. Wittenberg, P. Anzenbacher and L. Isaacs, J. Am. Chem. Soc., 2011, 133(44), 17966-17976.

8 B. Vinciguerra, L. Cao, J. R. Cannon, P. Y. Zavalij, C. Fenselau and L. Isaacs, J. Am. Chem. Soc., 2012, 134(31), 13133-13140.

9 B. Vinciguerra, P. Y. Zavalij and L. Isaacs, Org. Lett., 2015, 17(20), 5068-5071.

10 L. Gilberg, M. S. A. Khan, M. Enderesova and V. Sindelar, Org. Lett., 2014, 16(9), 2446-2449.

11 M. M. Ayhan, H. Karoui, M. Hardy, A. Rockenbauer, L. Charles, R. Rosas, K. Udachin, P. Tordo, D. Bardelang and O. Ouari, J. Am. Chem. Soc., 2015, 137(32), 10238-10245.

12 S. Y. Jon, N. Selvapalam, D. H. Oh, J.-K. Kang, S.-Y. Kim, Y. J. Jeon, J. W. Lee and K. Kim, J. Am. Chem. Soc., 2003, 125(34), 10186-10187.

13 N. Zhao, G. O. Lloyd and O. A. Scherman, Chem. Commun., 2012, 48(25), 3070 .

14 J. Svec, M. Necas and V. Sindelar, Angew. Chem., Int. Ed., 2010, 49(13), 2378-2381.

15 V. Havel, J. Svec, M. Wimmerova, M. Dusek, M. Pojarova and V. Sindelar, Org. Lett., 2011, 13(15), 4000-4003.

16 M. A. Yawer, V. Havel and V. Sindelar, Angew. Chem., Int. Ed., 2015, 54(1), 276-279.

17 M. Stancl, M. Hodan and V. Sindelar, Org. Lett., 2009, 11(18), 4184-4187.

18 W.-H. Huang, P. Y. Zavalij and L. Isaacs, Org. Lett., 2009, 11(17), 3918-3921. 
19 D. Ma, B. Zhang, U. Hoffmann, M. G. Sundrup, M. Eikermann and L. Isaacs, Angew. Chem., 2012, 124(45), 11520-11524.

20 B. Zhang and L. Isaacs, J. Med. Chem., 2014, 57(22), 9554-9563.

21 D. Ma, G. Hettiarachchi, D. Nguyen, B. Zhang, J. B. Wittenberg, P. Y. Zavalij, V. Briken and L. Isaacs, Nat. Chem., 2012, 4(6), 503-510.

22 T. Minami, N. A. Esipenko, B. Zhang, M. E. Kozelkova, L. Isaacs, R. Nishiyabu, Y. Kubo and P. Anzenbacher, J. Am. Chem. Soc., 2012, 134(49), 20021-20024.

23 J. B. Wittenberg, P. Y. Zavalij and L. Isaacs, Angew. Chem., Int. Ed., 2013, 52(13), 3690-3694.

24 J. B. Wittenberg and L. Isaacs, Supramol. Chem., 2014, 26(3-4), 157-167.
25 M. Zhang, L. Cao and L. Isaacs, Chem. Commun., 2014, 50(94), 14756-14759.

26 A. A. Bakibaev, T. I. Savchenko, V. D. Filimonov, A. Yu. Yagovkin and A. N. Novikov, Zh. Org. Khim., 1988, 24(12), 2581-2584.

27 A. A. Bakibaev and A. Yu. Yagovkin, Zh. Org. Khim., 1994, 30(1), 133-135.

28 Y. Unoh, K. Hirano, T. Satoh and M. Miura, Angew. Chem., Int. Ed., 2013, 52(49), 12975-12979.

29 V. K. Singh, H. Sharma, S. K. Singh and L. Gangwar, Chem. Biol. Drug Des., 2013, 82(1), 119-124.

30 R. P. Sijbesma, A. P. M. Kentgens and R. J. M. Nolte, J. Org. Chem., 1991, 56(10), 3199-3201. 